\title{
An ARMA Type Fuzzy Time Series Forecasting Method Based on Particle Swarm Optimization
}

\author{
Erol Egrioglu, ${ }^{1}$ Ufuk Yolcu, ${ }^{2}$ Cagdas Hakan Aladag, ${ }^{3}$ and Cem Kocak ${ }^{4}$ \\ ${ }^{1}$ Department of Statistics, Ondokuz Mayıs University, 55139 Samsun, Turkey \\ ${ }^{2}$ Department of Statistics, Ankara University, 06100 Ankara, Turkey \\ ${ }^{3}$ Department of Statistics, Hacettepe University, 06100 Ankara, Turkey \\ ${ }^{4}$ Medical High School, Hitit University, 19000 Çorum, Turkey
}

Correspondence should be addressed to Erol Egrioglu; erole@omu.edu.tr

Received 18 April 2013; Revised 21 June 2013; Accepted 22 June 2013

Academic Editor: Ming Li

Copyright (C) 2013 Erol Egrioglu et al. This is an open access article distributed under the Creative Commons Attribution License, which permits unrestricted use, distribution, and reproduction in any medium, provided the original work is properly cited.

\begin{abstract}
In the literature, fuzzy time series forecasting models generally include fuzzy lagged variables. Thus, these fuzzy time series models have only autoregressive structure. Using such fuzzy time series models can cause modeling error and bad forecasting performance like in conventional time series analysis. To overcome these problems, a new first-order fuzzy time series which forecasting approach including both autoregressive and moving average structures is proposed in this study. Also, the proposed model is a time invariant model and based on particle swarm optimization heuristic. To show the applicability of the proposed approach, some methods were applied to five time series which were also forecasted using the proposed method. Then, the obtained results were compared to those obtained from other methods available in the literature. It was observed that the most accurate forecast was obtained when the proposed approach was employed.
\end{abstract}

\section{Introduction}

Fuzzy time series firstly proposed by Song and Chissom [1] can be divided into two subclasses time variant and time invariant. Fuzzy time series method generally embodies three stages such as fuzzification, determination of fuzzy relations, and defuzzification stages. In the fuzzification stage, observations of time series are fuzzified. Fuzzy relations between the observations are defined in the stage of determination of fuzzy relations. Finally, the calculated fuzzy forecasts are defuzzified in the defuzzification phase. If one or more of these stages can be improved, the performance of the method will increase. Therefore, new fuzzy time series approaches have been proposed by making contributions to these stages in the literature.

In the literature, various methods have been proposed to fuzzify observations. While fixed interval lengths are used in Song and Chissom [1-3], Chen [4], Huarng [5], Chen [6], Tsaur et al. [7], Singh [8], and Egrioglu et al. [9, 10], dynamic length of interval lengths is employed in Huarng and Yu [11], Davari et al. [12], Yolcu et al. [13], Kuo et al. [14, 15], Park et al.
[16], Hsu et al. [17], and Huang et al. [18] in order to partition the universe of discourse. Also, Cheng et al. [19], Li et al. [20], Egrioglu et al. [21], Chen and Tanuwijaya [22], and Bang and Lee [23] used some methods based on clustering algorithms.

Song and Chissom [3] exploited feed forward neural networks to defuzzify fuzzy forecasts. Chen [4], Huarng [5], and Huarng and $\mathrm{Yu}$ [11] utilized centroid method in the defuzzification stage. Besides, Cheng et al. [24] and Aladag et al. [25] used a different technique based on adaptive expectation and centroid methods for fuzzification.

Establishing fuzzy relations plays important role in the forecasting performance of the method. In this phase, Song and Chissom [1] utilized fuzzy relationship matrix, and Sullivan and Woodall [26] used transition matrices based on Markov chain instead of fuzzy relationship matrix. Chen [4] suggested an approach in which fuzzy logic group relationship tables are employed to define fuzzy relations, and Cheng et al. [24], Huarng [5], Huarng and $\mathrm{Yu}$ [11], Yu [27], and Egrioglu et al. [21] also used fuzzy logic group relationship tables. Huarng and $\mathrm{Yu}$ [28] and Aladag et al. [29] preferred to utilize feed forward artificial neural networks in this stage. 
Aladag et al. [30] used a different type of artificial neural networks which is Elman recurrent neural networks. In the determination of fuzzy relations, Yu and Huarng [31] and Yolcu et al. [32] proposed different approaches in which feed forward artificial neural networks using membership values are used. Eğrioğlu [33] utilized genetic algorithms to define fuzzy relations. Moreover, many soft computing techniques have been used for forecasting in the literature. Yang et al. [34], and Yang et al. [35], and Yang et al. [36] are some of them.

In all of the studies mentioned previously, fuzzy time series forecasting models have autoregressive (AR) structure. However, many real life fuzzy time series can contain both autoregressive and moving average (MA) structures. Using forecasting models that have only AR structure for these time series can produce insufficient results. To analyze such time series, it is needed to use an ARMA type fuzzy time series forecasting model that includes both AR and MA structures. In this study, a novel fuzzy time series forecasting approach based on ARMA type fuzzy time series forecasting model is proposed to increase forecasting accuracy. Some fuzzy time series approaches in which fuzzy logic group relationship tables are employed disregard the fuzzy set theory since fuzzy sets' elements whose membership value is 1 are only taken into account in the fuzzification phase. Therefore, information loss occurs, and it is expected to decrease the explanation power of the model. In order to overcome these problems, the particle swarm optimization method is employed in the proposed approach to establish fuzzy relations. In addition, the computational cost of the proposed approach is very reasonable since it does not need to perform complex matrix operations when the particle swarm optimization method is used. Another advantage of the proposed method is that it uses the fuzzy $c$-means clustering method in the fuzzification phase. In the fuzzification phase of the fuzzy time series approach, there are some common problems such as the decision of the number of intervals, arbitrary determination of interval length, and arbitrary choice of degrees of membership. Since the fuzzy $c$-means clustering technique is employed in the proposed approach, it works in a systematic way.

In the real life, some time series have long-range dependence. Long-range-dependent time series is forecasted by using special linear models. ARFIMA models, which are used to forecast long-range-dependent time series, were firstly introduced by Granger and Joyeux [37]. General properties of ARFIMA models were given by Hosking [38, 39] and Beran [40]. First studies are concerned with estimation of fractional differencing parameter in fractional white noise processes. $R / S$ statistic was proposed in Hurst [41]. Egrioglu and Gunay [42], and Li [43], Li and Zhao [44] are important papers about fractional processes. In this study, time series are examined by using $R / S$ hypothesis test to determine long-range dependence in the application. The performance of proposed method is examined according to long-range dependence.

The next section presents basic definitions of fuzzy time series and fuzzy- $c$ means clustering method. In Section 3, the modified particle swarm optimization algorithm is given.
Section 4 introduces the proposed approach based on ARMA type fuzzy time series forecasting model and particle swarm optimization. The implementation is given in Section 5 . Finally, the last section concludes the paper.

\section{Fuzzy Time Series Basic Definitions and Fuzzy C-Means Clustering}

The fuzzy time series was firstly introduced by Song and Chissom [1]. The fundamental definitions of fuzzy time series, time variant, and time invariant fuzzy time series definitions are presented in what follows.

Definition 1. Let $Y(t)(t=\ldots, 0,1,2, \ldots)$, a subset of real numbers, be the universe of discourse on which fuzzy sets $f_{j}(t)$ are defined. If $F(t)$ is a collection of $f_{1}(t), f_{2}(t), \ldots$, then $F(t)$ is called a fuzzy time series defined on $Y(t)$.

Definition 2. Suppose that $F(t)$ is caused by $F(t-1)$ only; that is, $F(t-1) \rightarrow F(t)$. Then, this relation can be expressed as $F(t)=F(t-1) \circ R(t, t-1)$, where $R(t, t-1)$ is the fuzzy relationship between $F(t-1)$ and $F(t)$ and $F(t)=F(t-1)$ 。 $R(t, t-1)$ is called the first-order model of $F(t)$. "o" represents max-min composition of fuzzy sets.

Definition 3. Suppose that $R(t, t-1)$ is a first-order model of $F(t)$. If for any $t, R(t, t-1)$ is independent of $t$; that is, for any $t, R(t, t-1)=R(t-1, t-2)$; then $F(t)$ is called a time invariant fuzzy time series; otherwise, it is called a time variant fuzzy time series.

Song and Chissom [2] firstly introduced an algorithm based on the first-order model for forecasting time invariant $F(t)$. In Song and Chissom [2], the fuzzy relationship matrix $R(t, t-1)=R$ is obtained by many matrix operations. The fuzzy forecasts are obtained based on max-min composition as in what follows:

$$
F(t)=F(t-1) \circ R .
$$

The dimension of $R$ matrix depends on the number of fuzzy sets. The number of fuzzy sets equals the number of intervals that is composed of universe of discourse. The more fuzzy sets are used, the more matrix operations are needed to obtain $R$ matrix. When the number of fuzzy set is high, using the method proposed by Song and Chissom [2] considerably increases the computational cost.

For fuzzification, partition of universe of discourse method is used in the method proposed by Song and Chissom [1]. However, there are several problems related to the decomposition of universe of discourse. These problems are the determination of the number of intervals, arbitrarily choice of interval length, and membership degrees. In order to deal with these problems, Cheng et al. [19] and Li et al. [20] used fuzzy $c$-means clustering method for fuzzification. The fuzzy $c$-means clustering method was firstly introduced by Bezdek [45]. This clustering method is the most widely used one. In this method, fuzzy clustering is conducted by minimizing the least squared errors within groups. Let $u_{i j}$ be the membership values, $v_{i}$ the center of cluster, $n$ the number 
of variables, and $c$ the number of clusters. Then, the objective function, which is minimized in fuzzy clustering, is

$$
J_{\beta}(X, V, U)=\sum_{i=1}^{c} \sum_{j=1}^{n} u_{i j}^{\beta} d^{2}\left(x_{j}, v_{i}\right),
$$

where $\beta$ is a constant $(\beta>1)$ and called the fuzzy index. $d\left(x_{j}, v_{i}\right)$ is a similarity measure between an observation and the center of corresponding fuzzy cluster. The objective function $J_{\beta}$ is minimized subject to constraints given in what follows:

$$
\begin{gathered}
0 \leq u_{i j} \leq 1, \quad \forall i, j, \\
0<\sum_{j=1}^{n} u_{i j} \leq n, \quad \forall i, \\
\sum_{i=1}^{c} u_{i j}=1, \quad \forall j .
\end{gathered}
$$

In fuzzy $c$-means clustering method, to solve the minimization problem given previously, an iterative algorithm is used. In each iteration, the values of $v_{i}$ and $u_{i j}$ are updated by using the formulas given in (4) and (5), respectively:

$$
\begin{gathered}
v_{i}=\frac{\sum_{j=1}^{n} u_{i j}^{\beta} x_{j}}{\sum_{j=1}^{n} u_{i j}^{\beta}}, \\
u_{i j}=\frac{1}{\sum_{k=1}^{c}\left(d\left(x_{j}, v_{i}\right) / d\left(x_{j}, v_{k}\right)\right)^{2 /(\beta-1)}} .
\end{gathered}
$$

\section{The Particle Swarm Optimization}

Particle swarm optimization, which is a population-based heuristic algorithm, was firstly proposed by Kennedy and Eberhart [46]. Distinguishing feature of this heuristic algorithm is that it simultaneously examines different points in different regions of the solution space to find the global optimum solution. Local optimum traps can be avoided because of this feature.

In a few fuzzy time series studies, particle swarm optimization method has been exploited in fuzzification phase. While the particle swarm optimization method was employed by Davari et al. [12] for fuzzification in the firstorder fuzzy time series forecasting model, Kuo et al. [14] utilized the method in high-order models. In the fuzzification phase, Kuo et al. [15] utilized the particle swarm optimization method in both the first- and the high-order models. Park et al. [16] used the same method for fuzzification in a two-factor high-order model. However, the particle swarm optimization method has never been used to establish fuzzy logic relations in the literature. In time variant fuzzy time series forecasting method proposed in this study, the modified particle swarm optimization whose algorithm is given later is exploited. The modified particle swarm optimization algorithm has time varying inertia weight like in Shi and Eberhart [47]. In a similar way, this algorithm also has time varying acceleration coefficient like in Ma et al. [48].
Algorithm 4. The algorithm of the modified particle swarm optimization.

Step 1. Positions of each $k$ th $(k=1,2, \ldots, p n)$ particles' positions are randomly determined and kept in a vector $X_{k}$ given as follows:

$$
X_{k}=\left\{x_{k, 1}, x_{k, 2}, \ldots, x_{k, d}\right\}, \quad k=1,2, \ldots, p n,
$$

where $x_{i}^{k}(i=1,2, \ldots, d)$ represents $i$ th position of $k$ th particle. $p n$ and $d$ represent the number of particles in a swarm and positions, respectively.

Step 2. Velocities are randomly determined and stored in a vector $V_{k}$ given in what follows:

$$
V_{k}=\left\{v_{k, 1}, v_{k, 2}, \ldots, v_{k, d}\right\}, \quad k=1,2, \ldots, p n .
$$

Step 3. According to the evaluation function, $P$ best and $G$ best particles given in (8) and (9), respectively, are determined:

$$
\begin{gathered}
\text { Pbest }_{k}=\left(p_{k, 1}, p_{k, 2}, \ldots, p_{k, d}\right), \quad k=1,2, \ldots, p n, \\
\text { Gbest }=\left(p_{g, 1}, p_{g, 2}, \ldots, p_{g, d}\right),
\end{gathered}
$$

where $P$ best ${ }_{k}$ is a vector that stores the positions corresponding to the $k$ th particle's best individual performance and Gbest represents the best particle, which has the best evaluation function value, found so far.

Step 4. Let $c_{1}$ and $c_{2}$ represent cognitive and social coefficients, respectively, and $w$ is the inertia parameter. Let $\left(c_{1 i}, c_{1 f}\right),\left(c_{2 i}, c_{2 f}\right)$, and $\left(w_{1}, w_{2}\right)$ be the intervals which include possible values for $c_{1}, c_{2}$, and $w$, respectively. At each iteration, these parameters are calculated by using the formulas given in (10):

$$
\begin{gathered}
c_{1}=\left(c_{1 f}-c_{1 i}\right) \frac{t}{\max t}+c_{1 i}, \\
c_{2}=\left(c_{2 f}-c_{2 i}\right) \frac{t}{\max t}+c_{2 i}, \\
w=\left(w_{2}-w_{1}\right) \frac{\max t-t}{\max t}+w_{1},
\end{gathered}
$$

where max $t$ and $t$ represent maximum iteration number and current iteration number, respectively.

Step 5. Values of velocities and positions are updated by using the formulas given in (11) and (12), respectively.

$$
\begin{gathered}
v_{i, d}^{t+1}=\left[w \times v_{i, d}^{t}+c_{1} \times \operatorname{rand}_{1} \times\left(p_{i, d}-x_{i, d}\right)\right. \\
\left.+c_{2} \times \operatorname{rand}_{2} \times\left(p_{g, d}-x_{i, d}\right)\right], \\
x_{i, d}^{t+1}=x_{i, d}+v_{i, d}^{t+1},
\end{gathered}
$$

where $\operatorname{rand}_{1}$ and rand $_{2}$ are random values from the interval $\left[\begin{array}{ll}0 & 1\end{array}\right]$.

Step 6. Steps 3 to 5 are repeated until a predetermined maximum iteration number $(\max t)$ is reached. 
We would like to note that the aim of this study is not to propose a new particle swarm optimization algorithm. In the literature, it was shown that using some time varying parameters can increase the convergence speed of the algorithm (Shi and Eberhart [47]; Ma et al. [48]). Therefore, we just used both the time varying acceleration coefficient (Ma et al. [48]) and the time varying inertia weight (Shi and Eberhart [47]) in the standard particle swarm optimization as mentioned previously. Then, this modified particle swarm optimization method was utilized to calculate membership values in the fuzzy relationship matrix as addressed in the next section. It is not claimed in the paper that a better particle swarm optimization algorithm was improved.

\section{The Proposed Approach}

The fuzzy time series forecasting methods in the literature have only AR structure that includes lagged fuzzy variables. On the other hand, it will be wiser to use a model which includes both AR and MA structures in order to forecast real life time series that contain both structures. In the literature, we firstly define a new model which includes both AR and MA terms in Definition 5.

Definition 5. Let fuzzy time series $F(t)$ be caused by lagged fuzzy time series $F(t-1)$ and lagged absolute fuzzy error series $\varepsilon(t-1)$; then the relationship can be expressed as

$$
F(t-1), \quad \varepsilon(t-1) \longrightarrow F(t) .
$$

This model given in (13) is called an $\operatorname{ARMA}(1,1)$ fuzzy time series forecasting model. Thus, definition of fuzzy relations for this model is presented in Definition 6.

Definition 6. Suppose that $F(t)$ is caused by only $F(t-1)$ and $\varepsilon(t-1)$; that is, $F(t-1), \varepsilon(t-1) \rightarrow F(t)$. Then, this relation can be expressed as

$$
F(t)=\left(F(t-1) \circ R_{1}(t, t-1)\right) \cap\left(\varepsilon(t-1) \circ R_{2}(t, t-1)\right),
$$

where $R_{1}(t, t-1)\left(R_{1}=\left[r_{i j 1}\right], i=1,2, \ldots, c, j=1,2, \ldots, c\right)$ is the fuzzy relationship matrix between $F(t-1)$ and $F(t)$ and $R_{2}(t, t-1)\left(R_{2}=\left[r_{i j 2}\right], i=1,2, \ldots, c, j=1,2, \ldots, c\right)$ is the fuzzy relationship matrix between $\varepsilon(t-1)$ and $F(t)$.

In this study, a new fuzzy time series forecasting approach is suggested to forecast $\operatorname{ARMA}(1,1)$ fuzzy time series forecasting model in (13). The proposed approach provides some advantages which can be given as follows.

(i) Since the model given in (13) is employed in the proposed approach, it is more proper to use this method for forecasting real life time series that contain both AR and MA structures.

(ii) Since fuzzy $c$-means clustering method is utilized for fuzzification in the proposed approach, the number of intervals, the interval length, and the degrees of memberships is not arbitrarily determined in the fuzzification phase, so the proposed approach is a systematic method. (iii) The methods in the literature that exploit fuzzy logic group relationship tables disregard the fuzzy set theory since only some elements of fuzzy sets are taken into account in the fuzzification phase. Thus, information loss occurs and it is expected to decrease the explanation power of the model. However, in the proposed method, particle swarm optimization method is used to calculate membership values in the fuzzy relationship matrix, so information loss and decrease in explanatory power of the model are prevented.

(iv) In the proposed method, instead of using centroid method, a method which considers all membership degrees is employed. Therefore, information loss that occurs in the defuzzification stage is avoided.

(v) Since the proposed approach provides the advantages given previously, it is expected that the suggested method has high forecasting accuracy.

The algorithm of the proposed method is given later step by step.

Algorithm 7. The proposed method's algorithm.

Step 1. Fuzzify time series by using the fuzzy $c$-means clustering, and define fuzzy sets for absolute values of errors.

Let $c$ be the number of fuzzy set, such that $2 \leq c \leq n$. The fuzzy $c$-means clustering algorithm in which the number of fuzzy sets is $c$ is applied to the time series which consists of crisp values. After this application, the center of each fuzzy set is determined. Then, the degrees for each observation, which denote a degree of belonging to a fuzzy set for that observation, are calculated with respect to the obtained values of center of fuzzy sets. Finally, ordered fuzzy sets, $L_{r}(r=$ $1,2, \ldots, c)$, are obtained according to the ascending ordered centers, which are denoted by $v_{r}(r=1,2, \ldots, c)$.

Fuzzy sets for absolute values of errors are defined in accordance with predetermined length of interval. Subintervals that contain absolute values of errors are generated. The number of clusters is taken as $c$ which equals the number of cluster of time series. Thus, the number of subintervals is $c$. The upper bound of the last subinterval is always open. While the first subinterval has the minimum absolute error, the subsequent subintervals have comparatively greater absolute errors. Generally, subintervals can be defined by

$$
\begin{gathered}
u_{1}=[0, l a], \\
u_{2}=[l a, 2 \times l a], \ldots, u_{c}=[(c-1) \times l a, \infty],
\end{gathered}
$$

where la represents the length of interval. In accordance with these subintervals, fuzzy sets for absolute errors are defined as follows:

$$
\begin{gathered}
A_{1}=\frac{1}{u_{1}}+\frac{0.5}{u_{2}}, \quad A_{2}=\frac{0.5}{u_{1}}+\frac{1}{u_{2}}+\frac{0.5}{u_{3}}, \\
A_{c-1}=\frac{0.5}{u_{c-2}}+\frac{1}{u_{c-1}}+\frac{0.5}{u_{c}}, \quad A_{c}=\frac{0.5}{u_{c-1}}+\frac{1}{u_{c}} .
\end{gathered}
$$


Table 1: An example time series $X_{t}$.

\begin{tabular}{ccccccr}
\hline Date & $X_{t}$ & $v_{1}=13000$ & $v_{2}=13500$ & $\begin{array}{c}\text { Membership values } \\
v_{3}=14000\end{array}$ & $v_{4}=14500$ & 0 \\
& & 0.7 & 0.2 & 0.1 & 0 \\
1971 & 13055 & 0.2 & 0.7 & 0.1 & 0 \\
1972 & 13563 & 0.1 & 0.4 & 0.5 & 0 \\
1973 & 13867 & & & 0 & 0 \\
\hline
\end{tabular}

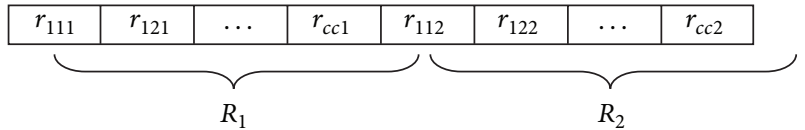

FIGURE 1: The structure of a particle.

Step 2. Determine the parameters of particle swarm optimization.

Some parameters of particle swarm optimization are possible intervals for social coefficient $\left(c_{1 i}, c_{1 f}\right)$, cognitive coefficient $\left(c_{2 i}, c_{2 f}\right)$, and inertia weight $\left(w_{1}, w_{2}\right)$. The other parameters are swarm size $(p n)$ and maximum iteration number $(\max t)$. Evaluation function is RMSE criterion which is computing as in what follows:

$$
\operatorname{RMSE}=\sqrt{\frac{\sum_{t=1}^{n}\left(x_{t}-\widehat{x}_{t}\right)^{2}}{n}},
$$

where $x_{t}$ is crisp time series, $\widehat{x}_{t}$ is defuzzified forecasts, and $n$ is the number of forecasts.

Step 3. Generate a random initial population.

Elements of each particle are elements of $R_{1}$ and $R_{2}$ fuzzy relation matrices given in Definition 6. Since both $R_{1}$ and $R_{2}$ matrices consist of $c^{2}$ elements $\left(R_{k}=\left[r_{i j k}\right], i=1,2, \ldots, c, j=\right.$ $1,2, \ldots, c, k=1,2)$, the number of elements in a particle equals to $2 c^{2}$. For the number of fuzzy sets $c$, representation of a particle is illustrated in Figure 1.

In this step, $r_{i j}(i, j=1,2, \ldots, c)$ values of all particles are randomly generated from the interval $[0,1]$ to generate a random initial population.

Step 4. Calculate the evaluation function values of all particles in the current swarm.

The method for calculating RMSE for any particle is given in Steps 4.1, 4.2, and 4.3.

Step 4.1. $R_{1}$ and $R_{2}$ fuzzy relation matrices are designed from positions of particles. Each $c$ position sets are the rows of $R_{1}$ and $R_{2}$ matrices.

Step 4.2. Fuzzy forecasts are calculated by using (14). After $R_{1}$ and $R_{2}$ relation matrices are estimated, fuzzy forecasts can be obtained by using fuzzy errors and fuzzy observations. When the first forecast is calculated, it is assumed that the error equals to zero since this assumption is also valid in conventional time series analysis.
For instance, some observations of a time series $X_{t}$, corresponding membership values of these observations, and the center values $\left(v_{i}, i=1,2,3,4,5\right)$ for each fuzzy set are given in Table 1.

Let the relations matrices be as follows:

$$
R_{1}=\left[\begin{array}{ccccc}
1 & 0.5 & 0 & 0 & 0 \\
0 & 0 & 1 & 0 & 0 \\
0 & 0 & 0 & 0.5 & 0 \\
0 & 0 & 0 & 0 & 0 \\
1 & 0 & 0 & 0 & 0
\end{array}\right], \quad R_{2}=\left[\begin{array}{ccccc}
1 & 0.5 & 0 & 0 & 0 \\
0.5 & 0 & 1 & 0 & 0 \\
0.3 & 0 & 0 & 0.05 & 0 \\
0 & 0 & 0 & 0 & 0 \\
1 & 0 & 0 & 0 & 0
\end{array}\right] \text {. }
$$

Thus, fuzzy forecast for 1972 can be calculated as follows:

$$
\begin{aligned}
\widehat{F}(1972)= & F(1971) \circ R_{1} \cap \mathcal{\varepsilon}(1971) \circ R_{2} \\
= & {\left[\begin{array}{lllll}
0.7 & 0.5 & 0.2 & 0 & 0
\end{array}\right] } \\
= & {\left[\begin{array}{lllll}
0.7 & 0.2 & 0.1 & 0 & 0
\end{array}\right] \circ\left[\begin{array}{ccccc}
1 & 0.5 & 0 & 0 & 0 \\
0 & 0 & 1 & 0 & 0 \\
0 & 0 & 0 & 0.5 & 0 \\
0 & 0 & 0 & 0 & 0 \\
1 & 0 & 0 & 0 & 0
\end{array}\right] } \\
& \cap\left[\begin{array}{lllll}
1 & 0.5 & 0 & 0 & 0
\end{array}\right] \circ\left[\begin{array}{ccccc}
1 & 0.5 & 0 & 0 & 0 \\
0.5 & 0 & 1 & 0 & 0 \\
0.3 & 0 & 0 & 0.05 & 0 \\
0 & 0 & 0 & 0 & 0 \\
1 & 0 & 0 & 0 & 0
\end{array}\right] .
\end{aligned}
$$

After this procedure, fuzzy forecasts are defuzzified by using the rules given in what follows.

(i) If the memberships of fuzzy forecast have only one maximum, then select the center of this cluster as the defuzzified forecasted value.

(ii) If memberships of fuzzy forecast have two or more consecutive maximums, then select arithmetic mean of centers of corresponding clusters as the defuzzified forecasted value.

(iii) Otherwise, standardize the fuzzy output, and use the center of the fuzzy sets as the forecasted value.

For example, defuzzified forecast for 1972 can be calculated as follows. Since the memberships of fuzzy forecast have only one maximum, defuzzified forecast value is taken as the center value $\left(v_{1}=13000\right)$ of the first fuzzy set which has the maximum membership value. This can be expressed by

$$
\widehat{X}_{1972}=\operatorname{Def}(\widehat{F}(1972))=13000 .
$$


Then, absolute error value for 1972 is calculated given as follows:

$$
E_{1972}=\left|X_{1972}-\widehat{X}_{1972}\right|=|13055-13000|=55 .
$$

Absolute error value is fuzzified by using corresponding fuzzy set which has the maximum membership value for the interval which includes this absolute error value. For instance, for the time series given in Table 1, when the interval length of absolute error is taken as 50, 5 subintervals are as follows:

$$
\begin{gathered}
u_{1}=[0,50], \quad u_{2}=[50,100], \quad u_{2}=[100,150], \\
u_{2}=[150,200], \quad u_{5}=[200, \infty) .
\end{gathered}
$$

Since the absolute error value 55 is in the second interval $u_{2}$, defuzzified absolute error is $A_{2}$. Thus, for 1972, the absolute error is obtained given as follows:

$$
\varepsilon(1972)=\left[\begin{array}{lllll}
0.5 & 1 & 0.5 & 0 & 0
\end{array}\right] .
$$

Then, the forecast for 1973 can be calculated as follows:

$$
\widehat{F}(1973)=F(1972) \circ R_{1} \cap \varepsilon(1972) \circ R_{2} .
$$

In the same way, other forecasts for other years can be obtained.

Step 4.3. RMSE is computed using the formula given in (17).

Step 5. Update cognitive coefficient $c_{1}$, social coefficient $c_{2}$, and inertia parameter $w$ at each iteration by using formulas in (10).

Step 6. New positions of the particles are calculated by using the formulas given in (11) and (12).

Step 7. Repeat Steps 4 to 7 until maximum iteration bound $(\max t)$ is reached.

\section{Application of the Proposed Method}

Firstly, the proposed method was applied to Alabama University enrollment data (1971-1992) that is well-known data in the literature. The enrollment data is presented in Table 2.

The algorithm of the proposed method was coded in MATLAB 7.9 version. In the application of the proposed method, we used seven fuzzy sets $(c=7)$ in Step 1 since the same number has been employed in other studies available in the literature (Cheng et al., 2008). The centers of clusters and the membership values which are obtained from FCM algorithm in Step 1 are given in Tables 3 and 4, respectively. In the fuzzification process of the absolute error, if the interval length is too small, aggregation will arise in the last fuzzy set. If it is too big, aggregation will occur in the first fuzzy set. Therefore, the length of interval for absolute error is picked
TABLE 2: The enrollment data.

\begin{tabular}{lccc}
\hline Years & Actual & Years & Actual \\
\hline 1971 & 13055 & 1982 & 15433 \\
1972 & 13563 & 1983 & 15497 \\
1973 & 13867 & 1984 & 15145 \\
1974 & 14696 & 1985 & 15163 \\
1975 & 15460 & 1986 & 15984 \\
1976 & 15311 & 1987 & 16859 \\
1977 & 15603 & 1988 & 18150 \\
1978 & 15861 & 1989 & 18970 \\
1979 & 16807 & 1990 & 19328 \\
1980 & 16919 & 1991 & 19337 \\
1981 & 16388 & 1992 & 18876 \\
\hline
\end{tabular}

TABLE 3: The centers of clusters obtained from FCM algorithm in Step 1.

\begin{tabular}{lcccccc}
\hline$v_{1}$ & $v_{2}$ & $v_{3}$ & $v_{4}$ & $v_{5}$ & $v_{6}$ & $v_{7}$ \\
13458.81 & 14700.56 & 15379.31 & 15904.31 & 16412.94 & 16889.11 & 19075.31 \\
\hline
\end{tabular}

as 300 . Then, 7 fuzzy sets for absolute errors can be defined as follows:

$$
\begin{gathered}
u_{1}=[0,300), \quad u_{2}=[300,600), \quad u_{3}=[600,900), \\
u_{4}=[900,1200), \quad u_{5}=[1200,1500) \\
u_{6}=[1500,1800), \quad u_{7}=[1800, \infty) .
\end{gathered}
$$

In the literature, there are no general rules to determine parameter values of particle swarm optimization. Parameter values for this method have been generally specified intuitively due to the data in most of the applications. Therefore, the parameters of particle swarm optimization used in this study were intuitively determined like in other studies available in the literature (Ma et al., 2006). The parameters of the modified particle swarm optimization are determined according to trial and error method. The different values of the parameters were employed. The best parameters of the modified particle swarm optimization are determined as follows: $\left(c_{1 i}, c_{1 f}\right)=(2,3),\left(c_{2 i}, c_{2 f}\right)=(2,3),\left(w_{1}, w_{1}\right)=$ $(1,2), p n=30$, and $\max t=200$. The optimal $R_{1}$ and $R_{2}$ matrices obtained from our methods are given later. The fuzzy and defuzzified forecasts of the proposed method are given in Table 5:

$$
R_{1}=\left[\begin{array}{lllllll}
1.0000 & 0.0000 & 1.0000 & 0.0000 & 1.0000 & 0.0000 & 0.4540 \\
0.0000 & 0.7525 & 0.0000 & 0.0458 & 0.0000 & 0.0000 & 0.0000 \\
0.3374 & 1.0000 & 1.0000 & 1.0000 & 1.0000 & 0.7000 & 1.0000 \\
1.0000 & 0.0000 & 1.0000 & 1.0000 & 0.8283 & 0.0000 & 0.0000 \\
0.4271 & 0.0000 & 1.0000 & 0.3627 & 0.0000 & 0.0000 & 1.0000 \\
0.0000 & 1.0000 & 1.0000 & 1.0000 & 0.1443 & 1.0000 & 0.4579 \\
0.0000 & 0.0000 & 1.0000 & 0.0000 & 1.0000 & 0.4002 & 0.0000
\end{array}\right],
$$


TABLE 4: The memberships of the observations obtained from FCM algorithm in Step 1.

\begin{tabular}{|c|c|c|c|c|c|c|c|}
\hline Years & Cluster 1 & Cluster 2 & Cluster 3 & Cluster 4 & Cluster 5 & Cluster 6 & Cluster 7 \\
\hline 1971 & 0.8768 & 0.0528 & 0.0265 & 0.0176 & 0.0127 & 0.0097 & 0.0039 \\
\hline 1972 & 0.9839 & 0.0083 & 0.0032 & 0.0019 & 0.0013 & 0.0010 & 0.0004 \\
\hline 1973 & 0.7128 & 0.1709 & 0.0519 & 0.0286 & 0.0183 & 0.0130 & 0.0044 \\
\hline 1974 & 0.0000 & 0.9999 & 0.0000 & 0.0000 & 0.0000 & 0.0000 & 0.0000 \\
\hline 1975 & 0.0015 & 0.0107 & 0.9463 & 0.0312 & 0.0068 & 0.0030 & 0.0005 \\
\hline 1976 & 0.0013 & 0.0121 & 0.9679 & 0.0128 & 0.0037 & 0.0018 & 0.0003 \\
\hline 1977 & 0.0063 & 0.0354 & 0.5767 & 0.3178 & 0.0440 & 0.0174 & 0.0024 \\
\hline 1978 & 0.0003 & 0.0014 & 0.0079 & 0.9824 & 0.0060 & 0.0017 & 0.0002 \\
\hline 1979 & 0.0006 & 0.0014 & 0.0031 & 0.0078 & 0.0410 & 0.9448 & 0.0012 \\
\hline 1980 & 0.0001 & 0.0002 & 0.0004 & 0.0009 & 0.0035 & 0.9948 & 0.0002 \\
\hline 1981 & 0.0001 & 0.0002 & 0.0006 & 0.0026 & 0.9939 & 0.0025 & 0.0001 \\
\hline 1982 & 0.0007 & 0.0052 & 0.9769 & 0.0127 & 0.0029 & 0.0013 & 0.0002 \\
\hline 1983 & 0.0029 & 0.0193 & 0.8823 & 0.0737 & 0.0146 & 0.0063 & 0.0010 \\
\hline 1984 & 0.0133 & 0.1919 & 0.6905 & 0.0658 & 0.0236 & 0.0125 & 0.0025 \\
\hline 1985 & 0.0118 & 0.1599 & 0.7306 & 0.0622 & 0.0219 & 0.0115 & 0.0022 \\
\hline 1986 & 0.0009 & 0.0036 & 0.0163 & 0.9388 & 0.0324 & 0.0073 & 0.0006 \\
\hline 1987 & 0.0001 & 0.0002 & 0.0004 & 0.0010 & 0.0045 & 0.9936 & 0.0002 \\
\hline 1988 & 0.0176 & 0.0325 & 0.0504 & 0.0767 & 0.1281 & 0.2432 & 0.4516 \\
\hline 1989 & 0.0004 & 0.0006 & 0.0009 & 0.0012 & 0.0017 & 0.0025 & 0.9928 \\
\hline 1990 & 0.0018 & 0.0029 & 0.0040 & 0.0053 & 0.0073 & 0.0104 & 0.9684 \\
\hline 1991 & 0.0019 & 0.0031 & 0.0042 & 0.0056 & 0.0077 & 0.0110 & 0.9664 \\
\hline 1992 & 0.0013 & 0.0022 & 0.0032 & 0.0044 & 0.0064 & 0.0098 & 0.9728 \\
\hline
\end{tabular}

TABLE 5: The forecasts produced by the proposed methods.

\begin{tabular}{|c|c|c|c|c|c|c|c|c|}
\hline \multirow{2}{*}{$\begin{array}{l}\text { Years } \\
1972\end{array}$} & \multicolumn{7}{|c|}{ Fuzzy forecasts } & \multirow{2}{*}{$\begin{array}{c}\text { Defuzzified forecasts } \\
13458.81\end{array}$} \\
\hline & 0.8768 & 0.5000 & 0.1475 & 0.0458 & 0.5824 & 0.0000 & 0.4540 & \\
\hline 1973 & 0.9839 & 0.5000 & 0.1475 & 0.0458 & 0.5824 & 0.0000 & 0.4540 & 13458.81 \\
\hline 1974 & 0.5000 & 0.7128 & 0.1709 & 0.1709 & 0.5000 & 0.5000 & 0.5000 & 14700.56 \\
\hline 1975 & 0.9999 & 0.2359 & 0.9999 & 0.0458 & 0.4169 & 0.0000 & 0.4540 & 15395.91 \\
\hline 1976 & 0.7084 & 0.3526 & 0.9463 & 0.0458 & 0.0312 & 0.0000 & 0.4540 & 15379.31 \\
\hline 1977 & 0.7084 & 0.3526 & 0.9679 & 0.0458 & 0.0128 & 0.0000 & 0.4540 & 15379.31 \\
\hline 1978 & 0.5767 & 0.3526 & 0.5767 & 0.0458 & 0.3178 & 0.0000 & 0.4540 & 15673.54 \\
\hline 1979 & 0.5122 & 0.5000 & 0.7212 & 0.0079 & 0.9824 & 0.0000 & 0.4540 & 16412.94 \\
\hline 1980 & 0.0078 & 0.0410 & 0.2108 & 0.0031 & 0.5000 & 0.0078 & 0.5000 & 17217.39 \\
\hline 1981 & 0.0009 & 0.0035 & 0.2108 & 0.0004 & 0.9019 & 0.0000 & 0.4540 & 16412.94 \\
\hline 1982 & 0.0026 & 0.5000 & 0.9939 & 0.0006 & 0.1144 & 0.0000 & 0.0026 & 15379.31 \\
\hline 1983 & 0.7084 & 0.3526 & 0.9769 & 0.0458 & 0.0127 & 0.0000 & 0.4540 & 15379.31 \\
\hline 1984 & 0.7084 & 0.3526 & 0.8823 & 0.0458 & 0.0737 & 0.0000 & 0.4540 & 15379.31 \\
\hline 1985 & 0.6905 & 0.3526 & 0.6905 & 0.0458 & 0.1919 & 0.0000 & 0.4540 & 15517.4 \\
\hline 1986 & 0.5000 & 0.3526 & 0.5000 & 0.5000 & 0.1599 & 0.5000 & 0.5000 & 15987.15 \\
\hline 1987 & 0.5122 & 0.5000 & 0.7212 & 0.0163 & 0.9388 & 0.0000 & 0.4540 & 16412.94 \\
\hline 1988 & 0.0010 & 0.0045 & 0.2108 & 0.0004 & 0.5000 & 0.0010 & 0.5000 & 17318.67 \\
\hline 1989 & 0.3198 & 0.1281 & 0.2108 & 0.0504 & 0.2432 & 0.0767 & 0.4516 & 19075.31 \\
\hline 1990 & 0.3198 & 0.0017 & 0.1446 & 0.0009 & 0.0025 & 0.0000 & 0.4540 & 19075.31 \\
\hline 1991 & 0.3198 & 0.0073 & 0.1446 & 0.0040 & 0.0104 & 0.0000 & 0.4540 & 19075.31 \\
\hline 1992 & 0.3198 & 0.0077 & 0.1446 & 0.0042 & 0.0110 & 0.0000 & 0.4540 & 19075.31 \\
\hline
\end{tabular}


TABLE 6: The obtained results for the enrollment data.

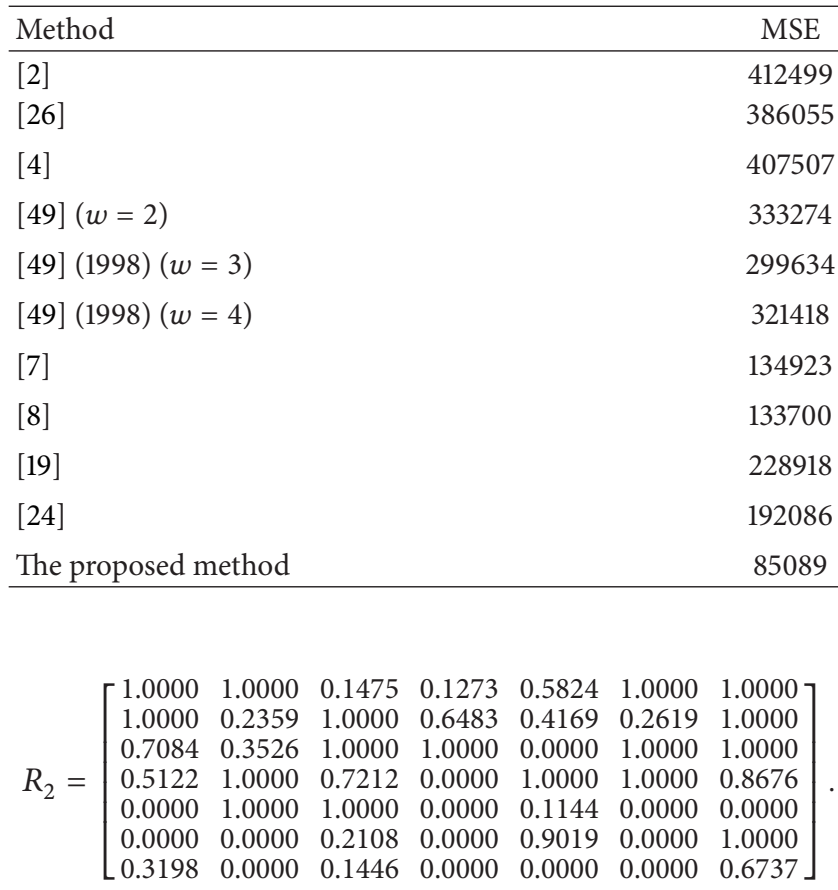

The mean square error (MSE) value of the proposed method is given in Table 6. For comparison, the forecasting results of some other well-known fuzzy time series forecasting approaches are also presented in Table 6 . When Table 6 was examined, it is seen that the proposed method gives the most accurate forecasts in terms of MSE criterion.

Secondly, to examine the forecasting performance of the proposed approach on test set, it was also applied to four different data sets. The first data set is index 100 in stocks and bonds exchange market of İstanbul (ISBEMI) whose daily observations are between May 20, 2008 and September 29, 2008. This data is called ISBEMI Set 1 . The second data is index 100 in stocks and bonds exchange market of İstanbul (ISBEMI) whose daily observations are between October 3, 2008 and December 31, 2008. The second data is called ISBEMI Set 2. The third one is ISBEMI Set 3, and its daily observations are from October 01, 2009 to December 312009. ISBEMI Set 1, ISBEMI Set 2, and ISBEMI Set 3 have 95, 59, and 63 observations, respectively. For comparison, these time series were also forecasted using other well-known fuzzy time series method proposed by Song and Chissom [2], Chen [4], Chen [6], Huarng [5], Huarng and Yu [11], and Aladag et al. [29]. In the implementation, the last 15 of ESBEMI Set 1 , 7 observations of ISBEMI Set 2, and 7 observations and 15 observations of ISBEMI Set 3 were used for test sets.

It is a well-known fact that there are no general rules to determine the parameters such as the length of interval or the number of fuzzy sets for some methods used in the implementation. Thus, related parameters were determined using trial and error method like in other studies available in the literature. To find the best length of interval for the methods introduced in [4], Chen [6], and Aladag et al. [29], the values between 200 and 2500 were examined with increment 100. The interval lengths in the methods given in Huarng [5] and Huarng and Yu [11] were determined when the methods were progressing because of the nature of these methods. The number of fuzzy sets was experienced between 5 and 25 for the proposed approach and Song and Chissom [2]. When the methods proposed by Chen [5] and Aladag et al. [29] were employed, models order 2, 3, 4, and 5 were examined since time series have daily observations. Finally, the number of neurons in hidden layer was changed from 1 to 10 when the approach proposed by Aladag et al. [29] was applied. After practicing, the forecasts obtained from the case where we have got the best result for the test data and the error criteria related to those forecasts are presented in Tables 7 and 8 for ISBEMI Sets 1 and 2, respectively.

For Table 7, the cases in which the superlative results were obtained are

(i) the number of the fuzzy sets was 12 for the SongChissom method [2];

(ii) the interval length was 1200 for the Chen method [4];

(iii) the interval length was 800 for the Huarng distribution-based method [5];

(iv) the interval length was 200 for the Huarng averagebased method [5];

(v) the ratio sample percentile was 0.5 for the Huarng and Yu ratio-based method [11];

(vi) the number of the fuzzy sets was five for the Cheng et al. method [19];

(vii) the number of the fuzzy sets was 11 and the number of the neurons in the hidden layer was five for Yolcu et al. [32];

(viii) the number of the fuzzy sets was 5 in the proposed method.

For Table 8, the cases in which the superlative results were obtained are

(i) when the number of fuzzy sets is 12 , for the method of Song and Chissom [2];

(ii) when the length of interval is 1900 for the method of [4];

(iii) when the length of interval is 2200 and the model order is 2 for the method of Chen [6];

(iv) when the length of interval is 800 for the method of Huarng distribution based [5];

(v) when the length of interval is 200 for the method of Huarng average based [5];

(vi) when the ratio sample percentile is 0.5 for the method of Huarng and Yu ratio based [11];

(vii) when the length of interval is 1000, the model order is 2 , and number of neurons in hidden layer is 7 for the method proposed by Aladag et al. [29];

(viii) when the number of fuzzy sets is 5 in the proposed method. 
TABLE 7: The obtained results for ISBEMI Set 1.

\begin{tabular}{|c|c|c|c|c|c|c|c|c|}
\hline Date & The test data & {$[2]$} & {$[4]$} & $\begin{array}{l}\text { [5] distribution-based } \\
\text { method }\end{array}$ & $\begin{array}{l}\text { [5] average-based } \\
\text { method }\end{array}$ & [11] & [32] & $\begin{array}{l}\text { The proposed } \\
\text { method }\end{array}$ \\
\hline 23.12 .2008 & 26294 & 26410 & 26400 & 26200 & 26100 & 26091 & 26274 & 26343 \\
\hline 24.12.2008 & 26055 & 26410 & 26400 & 26200 & 26367 & 26091 & 26273 & 26292 \\
\hline 25.12 .2008 & 26059 & 26410 & 26400 & 26200 & 26100 & 26091 & 26339 & 25983 \\
\hline 26.12.2008 & 26499 & 26410 & 26400 & 26200 & 26100 & 26091 & 26337 & 26255 \\
\hline 29.12.2008 & 26424 & 26410 & 26400 & 26200 & 26500 & 26608 & 26565 & 26513 \\
\hline 30.12 .2008 & 26411 & 26410 & 26400 & 26200 & 26500 & 26608 & 26429 & 26192 \\
\hline 31.12 .2008 & 26864 & 26410 & 26400 & 26200 & 26500 & 26091 & 26460 & 26513 \\
\hline \multicolumn{2}{|c|}{ RMSE } & 261.0109 & 259.7625 & 310.4688 & 251.2390 & 354.7194 & 219.2734 & 207.91 \\
\hline \multicolumn{2}{|c|}{ MAPE } & 0.0075 & 0.0075 & 0.0096 & 0,0080 & 0.0098 & 0.0067 & 0.0067 \\
\hline \multicolumn{2}{|r|}{ DA } & 0.6667 & 0.6667 & 0.8333 & 0.5000 & 0.5000 & 0.6667 & 0.6667 \\
\hline
\end{tabular}

TABLE 8: The obtained results for ISBEMI Set 2.

\begin{tabular}{|c|c|c|c|c|c|c|c|c|c|}
\hline Date & The test data & {$[2]$} & {$[4]$} & {$[6]$} & $\begin{array}{l}\text { [5] distribution-based } \\
\text { method }\end{array}$ & $\begin{array}{l}\text { [5] average-based } \\
\text { method }\end{array}$ & {$[11]$} & [29] & $\begin{array}{c}\text { The proposed } \\
\text { method }\end{array}$ \\
\hline 09.09 .2008 & 40124.6 & 39958.4 & 40550 & 39700 & 40000 & 39967 & 40547 & 40500 & 40457.3 \\
\hline 10.09.2008 & 39295.0 & 40294.2 & 40550 & 37500 & 40000 & 39800 & 40126 & 39500 & 40457.3 \\
\hline 11.09.2008 & 37388.1 & 39431.8 & 38650 & 37500 & 40000 & 39100 & 39603 & 39500 & 39335.3 \\
\hline 12.09 .2008 & 37033.9 & 37656.1 & 36750 & 37500 & 37200 & 37500 & 37602 & 38500 & 39335.3 \\
\hline 15.09.2008 & 35081.4 & 37272.4 & 36750 & 37500 & 37200 & 37100 & 36955 & 37500 & 36339.1 \\
\hline 16.09 .2008 & 33736.4 & 35024.0 & 34850 & 35300 & 34533 & 34700 & 34881 & 35500 & 33234.8 \\
\hline 17.09 .2008 & 32727.6 & 33954.4 & 33900 & 33100 & 34400 & 33700 & 34037 & 33500 & 33234.8 \\
\hline 18.09.2008 & 32216.4 & 33638.4 & 33900 & 33100 & 32400 & 32700 & 32266 & 32500 & 33234.8 \\
\hline 19.09.2008 & 36370.2 & 37746.4 & 33900 & 35300 & 32400 & 32300 & 32221 & 35500 & 36339.1 \\
\hline 22.09 .2008 & 36183.6 & 36450.8 & 36750 & 35300 & 36800 & 37700 & 36711 & 35500 & 36339.1 \\
\hline 23.09.2008 & 35454.2 & 36166.4 & 36750 & 35300 & 36800 & 36100 & 35225 & 35500 & 36339.1 \\
\hline 24.09.2008 & 35177.1 & 35072.6 & 34850 & 35300 & 35600 & 35100 & 35634 & 35500 & 33234.8 \\
\hline 25.09 .2008 & 36361.8 & 35024.0 & 34850 & 35300 & 34533 & 34700 & 34881 & 35500 & 36339.1 \\
\hline 26.09.2008 & 36556.6 & 36450.8 & 36750 & 35300 & 36800 & 37700 & 36711 & 37500 & 36339.1 \\
\hline 29.09.2008 & 36051.3 & 36450.8 & 36750 & 37500 & 36800 & 35900 & 36711 & 35500 & 36339.1 \\
\hline \multicolumn{2}{|c|}{ RMSE } & 1155.3 & 1229.7 & 1143.6 & 1579.1 & 1483.0 & 1484.9 & 1145.9 & 1107.2 \\
\hline \multicolumn{2}{|c|}{ MAPE } & 0.0268 & 0.0299 & 0.0261 & 0.0327 & 0.0308 & 0.0298 & 0.0255 & 0.0233 \\
\hline \multicolumn{2}{|c|}{ DA } & 0.4286 & 0.5000 & 0.5714 & 0.4286 & 0.7143 & 0.4286 & 0.6429 & 0.5714 \\
\hline
\end{tabular}

TABLE 9: The obtained results (last 7 observations are test set) for ISBEMI Set 3.

\begin{tabular}{|c|c|c|c|c|c|c|c|c|}
\hline Date & The test data & {$[2]$} & {$[4]$} & $\begin{array}{l}\text { [5] distribution-based } \\
\text { method }\end{array}$ & $\begin{array}{c}\text { [5] average-based } \\
\text { method }\end{array}$ & [11] & [32] & $\begin{array}{l}\text { The proposed } \\
\text { method }\end{array}$ \\
\hline 23.12.2009 & 51162 & 51137 & 52150 & 51900 & 51573 & 51033 & 51317 & 51684 \\
\hline 24.12.2009 & 51461 & 51137 & 50850 & 50700 & 50373 & 51033 & 51317 & 51109 \\
\hline 25.12.2009 & 51661 & 51137 & 50850 & 50700 & 51240 & 51033 & 51317 & 51684 \\
\hline 28.12 .2009 & 51619 & 51137 & 52150 & 51900 & 51573 & 51033 & 51317 & 51684 \\
\hline 29.12.2009 & 51786 & 51137 & 52150 & 51900 & 51573 & 51033 & 51317 & 51684 \\
\hline 30.12 .2009 & 51668 & 51137 & 52150 & 51900 & 51773 & 52004 & 51317 & 51684 \\
\hline 31.12 .2009 & 52825 & 51137 & 52150 & 51900 & 51573 & 51033 & 51317 & 51684 \\
\hline \multicolumn{2}{|c|}{ RMSE } & 771.0155 & 666.5039 & 659.9450 & 671.4803 & 830.4429 & 640.4131 & 494.5180 \\
\hline \multicolumn{2}{|c|}{ MAPE } & 0.0116 & 0.0123 & 0.0111 & 0.0097 & 0.0128 & 0.0090 & 0.0061 \\
\hline \multicolumn{2}{|c|}{$\mathrm{DA}$} & 0.3333 & 0.3333 & 0.3333 & 0.3333 & 0.1667 & 0.5000 & 0.6667 \\
\hline
\end{tabular}


TABLE 10: The obtained results (last 15 observations are test set) for ISBEMI Set 3.

\begin{tabular}{|c|c|c|c|c|c|c|c|c|}
\hline Date & The test data & {$[2]$} & {$[4]$} & $\begin{array}{c}\text { [5] distribution-based } \\
\text { method }\end{array}$ & $\begin{array}{c}\text { [5] average-based } \\
\text { method }\end{array}$ & [11] & {$[32]$} & $\begin{array}{c}\text { The proposed } \\
\text { method }\end{array}$ \\
\hline 11.12 .2009 & 49386 & 49872 & 50250 & 49500 & 49100 & 49748 & 49516 & 49982.39 \\
\hline 14.12.2009 & 50198 & 48606 & 48750 & 49500 & 49300 & 49316 & 50064 & 49982.39 \\
\hline 15.12.2009 & 50450 & 49872 & 50250 & 49900 & 50500 & 50405 & 50942 & 50833.82 \\
\hline 16.12.2009 & 50817 & 50294 & 50250 & 49900 & 48900 & 48886 & 50217 & 50833.82 \\
\hline 17.12.2009 & 49963 & 50294 & 50250 & 50300 & 50900 & 48886 & 49641 & 50833.82 \\
\hline 18.12.2009 & 50138 & 49872 & 50250 & 49900 & 49900 & 49748 & 49619 & 49613.83 \\
\hline 21.12.2009 & 51281 & 49872 & 50250 & 49900 & 50500 & 50405 & 50932 & 51390.68 \\
\hline 22.12.2009 & 51533 & 51137 & 51000 & 50300 & 50967 & 50625 & 50817 & 51390.68 \\
\hline 23.12.2009 & 51162 & 51137 & 51000 & 51900 & 51500 & 51065 & 51100 & 51390.68 \\
\hline 24.12.2009 & 51461 & 51137 & 51000 & 50300 & 50550 & 50625 & 50646 & 51390.68 \\
\hline 25.12.2009 & 51661 & 51137 & 51000 & 50300 & 51500 & 51065 & 51073 & 51390.68 \\
\hline 28.12.2009 & 51619 & 51137 & 51000 & 51900 & 51700 & 51065 & 51117 & 51390.68 \\
\hline 29.12.2009 & 51786 & 51137 & 51000 & 51900 & 51700 & 51065 & 51114 & 51390.68 \\
\hline 30.12 .2009 & 51668 & 51137 & 51000 & 51900 & 51700 & 51963 & 51119 & 51390.68 \\
\hline 31.12 .2009 & 52825 & 51137 & 51000 & 51900 & 51700 & 51065 & 51117 & 51390.68 \\
\hline \multicolumn{2}{|c|}{ RMSE } & 810.8493 & 820.5748 & 815.9879 & 760.7710 & 917.1070 & 662.3497 & 522.0852 \\
\hline \multicolumn{2}{|c|}{ MAPE } & 0.0128 & 0.0133 & 0.0134 & 0.0110 & 0.0147 & 0.0106 & 0.0075 \\
\hline \multicolumn{2}{|c|}{$\mathrm{DA}$} & 0.2857 & 0.5000 & 0.2857 & 0.5000 & 0.3571 & 0.5000 & 0.6429 \\
\hline
\end{tabular}

The best cases for the results given in Table 9 resulted when

(i) Song-Chissom method [2] was applied with nine fuzzy sets;

(ii) interval length was 1300 for the Chen method [4];

(iii) interval length was 800 for the Huarng distributionbased method [5];

(iv) interval length was 200 for the Huarng average-based method [5];

(v) ratio sample percentile was 0.50 for the Huarng and Yu ratio-based method [11];

(vi) the number of the fuzzy sets was 13 and the number of the neurons in the hidden layer was seven for Yolcu et al. [32];

(vii) when the number of fuzzy sets is 5 in the proposed method. when

The best cases for the results given in Table 10 resulted

(i) Song-Chissom [2] method was applied with nine fuzzy sets;

(ii) interval length was 1500 for the Chen method [4];

(iii) interval length was 800 for the Huarng distributionbased method [5];

(iv) interval length was 200 for the Huarng average-based method [5];

(v) ratio sample percentile was 0.50 for the Huarng and Yu ratio-based method [11]; (vi) the number of the fuzzy sets was seven and the number of the neurons in the hidden layer was three for Yolcu et al. [32];

(vii) the number of the fuzzy sets was five in the proposed method.

When Tables 6-10 are examined, it is obvious that the most accurate forecasts are obtained for all data sets when the proposed forecasting approach is used.

\section{Conclusion and Discussion}

In this study, an ARMA type fuzzy time series forecasting model is firstly introduced in the literature. In addition, to analyze this model, a novel approach based on fuzzy $c$-means and particle swarm optimization methods is suggested in this study. To show the forecasting performance of the proposed forecasting approach, the enrollments of Alabama University are applied to a well-known data and obtained forecasting results are compared to those produced by other fuzzy time series forecasting methods available in the literature. In addition, to evaluate the forecasting performance of the proposed forecasting approach on test set, two different time series are forecasted by utilizing the proposed method and other approaches available in the literature. As a result of the comparison, it is observed that the proposed approach gives the most accurate forecasts.

In the literature, the proposed method is the first method based on a fuzzy time series forecasting model which contains both $\mathrm{AR}$ and MA terms. In the linear stochastic ARMA models, the $\mathrm{AR}(\infty)$ model is equal to MA(1) model. But this result is only valid for linear ARMA models. There is no such 
TABLE 11: Results of R/S test.

\begin{tabular}{lcc}
\hline Data & $\mathrm{R} / \mathrm{S}$ statistics & $P<0.01$ \\
\hline ISBEMI Set 1 & 1.2966 & No \\
ISBEMI Set 2 & 1.5937 & No \\
ISBEMI Set 3 & 1.6523 & No \\
Enrollment data & 1.0969 & No \\
\hline
\end{tabular}

kind of result for fuzzy time series model, artificial neural network model, and nonlinear stochastic models. Because of this, adding MA terms to fuzzy time series forecasting model is really important. Also, in the proposed method, particle swarm optimization method is used to calculate membership values in the fuzzy relationship matrix, so information loss and decrease in explanatory power of the model are prevented. Besides, since fuzzy $c$-means clustering method is employed in the fuzzification process, the number of intervals, the interval length, and the degrees of memberships are not arbitrarily determined, so the proposed approach works in a systematic way. In addition, information loss which occurs in the defuzzification stage is avoided by using a method which takes all membership degrees into account instead of using centroid method. Therefore, the proposed method has high forecasting accuracy.

Moreover, long-range dependence was determined for all time series by using $R / S$ tests, and results are given in the appendix. All of the time series are short-range dependent. In the future studies, the performance of the proposed method will be able to research for long-range time series. But in the proposed fuzzy time series method, any linear model was not used. Fuzzy time series methods can be used to forecast nonlinear time series. In the fuzzy time series methods, the relations are employed instead of functions.

The proposed forecasting approach is suggested to forecast a first-order model including both AR and MA terms. In future studies, high-order models can be defined. Then, it is possible to extend the proposed approach to forecast high order models.

\section{Appendix}

$R / S$ test was applied to five time series to determine longrange dependence. The test results are given in Table 11. As a result of hypotheses tests, all data sets are shortrange dependent. The tests were applied in S-PLUS package program.

\section{Acknowledgments}

The authors would like to thank the reviewers for their helpful comments and opinions. This work was supported by "The Scientific and Technological Research Council of Turkey (TUBITAK)," Turkey, under Project no. 210T150.

\section{References}

[1] Q. Song and B. S. Chissom, "Fuzzy time series and its models," Fuzzy Sets and Systems, vol. 54, no. 3, pp. 269-277, 1993.
[2] Q. Song and B. S. Chissom, "Forecasting enrollments with fuzzy time series-part I," Fuzzy Sets and Systems, vol. 54, pp. 1-10, 1993.

[3] Q. Song and B. S. Chissom, "Forecasting enrollments with fuzzy time series-part II," Fuzzy Sets and Systems, vol. 62, no. 1, pp. $1-8,1994$.

[4] S. M. Chen, "Forecasting enrollments based on fuzzy time series," Fuzzy Sets and Systems, vol. 81, no. 3, pp. 311-319, 1996.

[5] K. Huarng, "Effective lengths of intervals to improve forecasting in fuzzy time series," Fuzzy Sets and Systems, vol. 123, no. 3, pp. 387-394, 2001.

[6] S. Chen, "Forecasting enrollments based on high-order fuzzy time series," Cybernetics and Systems, vol. 33, no. 1, pp. 1-16, 2002.

[7] R.-C. Tsaur, J. C. O. Yang, and H.-F. Wang, "Fuzzy relation analysis in fuzzy time series model," Computers \& Mathematics with Applications, vol. 49, no. 4, pp. 539-548, 2005.

[8] S. R. Singh, "A simple method of forecasting based on fuzzy time series," Applied Mathematics and Computation, vol. 186, no. 1, pp. 330-339, 2007.

[9] E. Egrioglu, C. H. Aladag, U. Yolcu, V. R. Uslu, and M. A. Basaran, "Finding an optimal interval length in high order fuzzy time series," Expert Systems with Applications, vol. 37, no. 7, pp. 50525055,2010

[10] E. Egrioglu, C. H. Aladag, M. A. Basaran, U. Yolcu, and V. R. Uslu, "A new approach based on the optimization of the length of intervals in fuzzy time series," Journal of Intelligent and Fuzzy Systems, vol. 22, no. 1, pp. 15-19, 2011.

[11] K. Huarng and T. H. Yu, "Ratio-based lengths of intervals to improve fuzzy time series forecasting," IEEE Transactions on Systems, Man, and Cybernetics B, vol. 36, no. 2, pp. 328-340, 2006.

[12] S. Davari, M. H. F. Zarandi, and I. B. Turksen, "An improved fuzzy time series forecasting model based on particle swarm intervalization," in Proceedings o the Annual Meeting of the North American Fuzzy Information Processing Society (NAFIPS '09), Cincinnati, Ohio, USA, June 2009.

[13] U. Yolcu, E. Egrioglu, V. R. Uslu, M. A. Basaran, and C. H. Aladag, "A new approach for determining the length of intervals for fuzzy time series," Applied Soft Computing Journal, vol. 9, no. 2, pp. 647-651, 2009.

[14] I. H. Kuo, S. J. Horng, T. W. Kao, T. L. Lin, C. L. Lee, and Y. Pan, "An improved method for forecasting enrollments based on fuzzy time series and particle swarm optimization," Expert Systems with Applications, vol. 36, no. 3, pp. 6108-6117, 2009.

[15] I. H. Kuo, S. J. Horng, Y. H. Chen et al., "Forecasting TAIFEX based on fuzzy time series and particle swarm optimization," Expert Systems with Applications, vol. 37, no. 2, pp. 1494-1502, 2010.

[16] J. Park, D. Lee, C. Song, and M. Chun, “TAIFEX and KOSPI 200 forecasting based on two-factors high-order fuzzy time series and particle swarm optimization," Expert Systems with Applications, vol. 37, no. 2, pp. 959-967, 2010.

[17] L. Hsu, S. Horng, T. Kao et al., "Temperature prediction and TAIFEX forecasting based on fuzzy relationships and MTPSO techniques," Expert Systems with Applications, vol. 37, no. 4, pp. 2756-2770, 2010.

[18] Y. Huang, S. Horng, T. Kao et al., "An improved forecasting model based on the weighted fuzzy relationship matrix combined with a PSO adaptation for enrollments," International Journal of Innovative Computing, Information and Control, vol. 7, no. 7A, pp. 4027-4046, 2011. 
[19] C. Cheng, G. Cheng, and J. Wang, "Multi-attribute fuzzy time series method based on fuzzy clustering," Expert Systems with Applications, vol. 34, no. 2, pp. 1235-1242, 2008.

[20] S.-T. Li, Y.-C. Cheng, and S.-Y. Lin, "A FCM-based deterministic forecasting model for fuzzy time series," Computers \& Mathematics with Applications, vol. 56, no. 12, pp. 3052-3063, 2008.

[21] E. Egrioglu, C. H. Aladag, U. Yolcu, V. R. Uslu, and N. A. Erilli, "Fuzzy time series forecasting method based on GustafsonKessel fuzzy clustering," Expert Systems with Applications, vol. 38, no. 8, pp. 10355-10357, 2011.

[22] S. Chen and K. Tanuwijaya, "Fuzzy forecasting based on highorder fuzzy logical relationships and automatic clustering techniques," Expert Systems with Applications, vol. 38, no. 12, pp. 15425-15437, 2011.

[23] Y. Bang and C. Lee, "Fuzzy time series prediction using hierarchical clustering algorithms," Expert Systems with Applications, vol. 38, no. 4, pp. 4312-4325, 2011.

[24] C. Cheng, T. Chen, H. J. Teoh, and C. Chiang, "Fuzzy timeseries based on adaptive expectation model for TAIEX forecasting," Expert Systems with Applications, vol. 34, no. 2, pp. 11261132, 2008.

[25] C. H. Aladag, U. Yolcu, and E. Egrioglu, "A high order fuzzy time series forecasting model based on adaptive expectation and artificial neural networks," Mathematics and Computers in Simulation, vol. 81, no. 4, pp. 875-882, 2010.

[26] J. Sullivan and W. H. Woodall, "A comparison of fuzzy forecasting and Markov modeling," Fuzzy Sets and Systems, vol. 64, no. 3, pp. 279-293, 1994.

[27] H. Yu, "Weighted fuzzy time series models for TAIEX forecasting," Physica A, vol. 349, no. 3-4, pp. 609-624, 2005.

[28] K. Huarng and T. H. Yu, "The application of neural networks to forecast fuzzy time series," Physica A, vol. 363, no. 2, pp. 481-491, 2006.

[29] C. H. Aladag, M. A. Basaran, E. Egrioglu, U. Yolcu, and V. R. Uslu, "Forecasting in high order fuzzy times series by using neural networks to define fuzzy relations," Expert Systems with Applications, vol. 36, no. 3, pp. 4228-4231, 2009.

[30] C. H. Aladag, E. Egrioğlu, S. Gunay, and U. Yolcu, "High order fuzzy time series model and stock exchange application," Anadolu Üni," Anadolu Üniversitesi Bilim ve Teknoloji Dergisi, vol. 11, no. 2, pp. 95-101, 2010.

[31] T. H. Yu and K. Huarng, "A neural network-based fuzzy time series model to improve forecasting," Expert Systems with Applications, vol. 37, no. 4, pp. 3366-3372, 2010.

[32] U. Yolcu, C. H. Aladag, E. Egrioglu, and V. R. Uslu, “Time series forecasting with a novel fuzzy time series approach: an example for Istanbul stock market," Journal of Statistical Computation and Simulation, vol. 83, no. 4, 2013.

[33] E. Eğrioğlu, "A new time-invariant fuzzy time series forecasting method based on genetic algorithm," Advances in Fuzzy Systems, vol. 2012, Article ID 785709, 6 pages, 2012.

[34] X. H. Yang, Z. F. Yang, and Z. Y. Shen, "GHHAGA for environmental systems optimization," Journal of Environmental Informatics, vol. 5, no. 1, pp. 36-41, 2005.

[35] X. Yang, Z. Yang, X. Yin, and J. Li, "Chaos gray-coded genetic algorithm and its application for pollution source identifications in convection-diffusion equation," Communications in Nonlinear Science and Numerical Simulation, vol. 13, no. 8, pp. 1676-1688, 2008.

[36] X. H. Yang, D. X. She, Z. F. Yang, Q. H. Tang, and J. Q. Li, "Chaotic bayesian method based on multiple criteria decision making (MCDM) for forecasting nonlinear hydrological time series," International Journal of Nonlinear Sciences and Numerical Simulation, vol. 10, no. 11-12, pp. 1595-1610, 2009.

[37] C. W. J. Granger and R. Joyeux, "An introduction to long-memory time series models and fractional differencing," Journal of Time Series Analysis, vol. 1, no. 1, pp. 15-29, 1980.

[38] J. R. M. Hosking, "Fractional differencing," Biometrika, vol. 68, no. 1, pp. 165-176, 1981.

[39] J. R. M. Hosking, "Modeling persistence in hydrological time series using fractional differencing," Water Resources Research, vol. 20, no. 12, pp. 1898-1908, 1984.

[40] J. Beran, Statistics for Long-Memory Processes, vol. 61, Chapman and Hall, New York, NY, USA, 1994.

[41] H. E. Hurst, "Long-term storage capacity of reservoirs," Transactions of the American Society of Civil Engineers, vol. 116, pp. 770-779, 1951.

[42] E. Egrioglu and S. Gunay, "Two new Mmethods for bayesian model selection in ARFIMA models," Expert Systems with Applications, vol. 37, pp. 8359-8364, 2010.

[43] M. Li, "Fractal time series-a tutorial review," Mathematical Problems in Engineering, vol. 2010, Article ID 157264, 26 pages, 2010.

[44] M. Li and W. Zhao, "On 1/f noise," Mathematical Problems in Engineering, vol. 2012, Article ID 673648, 23 pages, 2012.

[45] J. C. Bezdek, Pattern Recognition with Fuzzy Objective Function Algorithms, Plenum Press, New York, NY, USA, 1981.

[46] J. Kennedy and R. Eberhart, "Particle swarm optimization," in Proceedings of the IEEE International Conference on Neural Networks, pp. 1942-1948, IEEE Press, Piscataway, NJ, USA, December 1995.

[47] Y. Shi and R. C. Eberhart, "Empirical study of particle swarm optimization," in Proceedings of the Congress on Evolutionary Computation (CEC '99), vol. 3, pp. 1950-1945, 1999.

[48] Y. Ma, C. Jiang, Z. Hou, and C. Wang, "The formulation of the optimal strategies for the electricity producers based on the particle swarm optimization algorithm," IEEE Transactions on Power Systems, vol. 21, no. 4, pp. 1663-1671, 2006.

[49] J. Hwang, S. Chen, and C. Lee, "Handling forecasting problems using fuzzy time series," Fuzzy Sets and Systems, vol. 100, no. 1-3, pp. 217-228, 1998. 


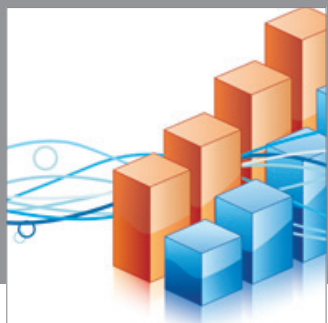

Advances in

Operations Research

mansans

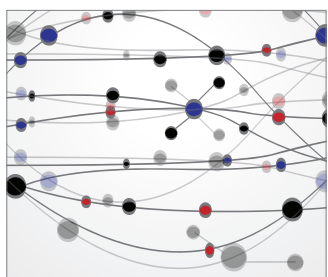

The Scientific World Journal
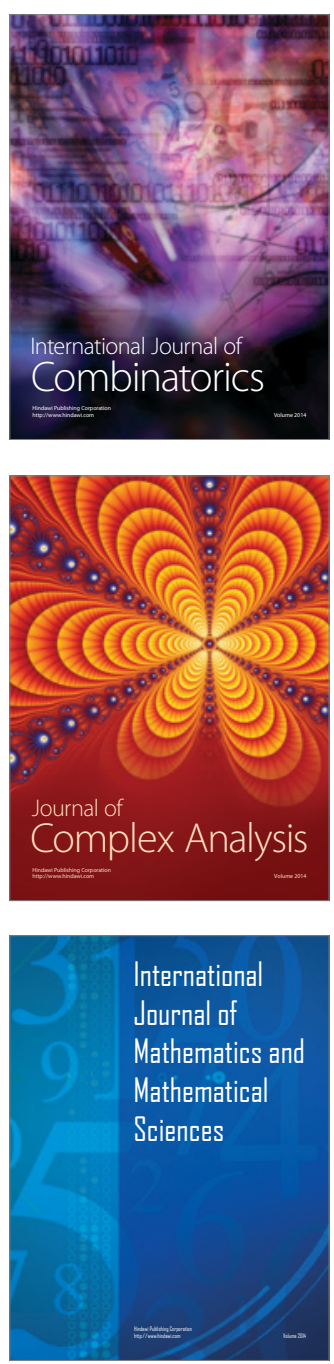
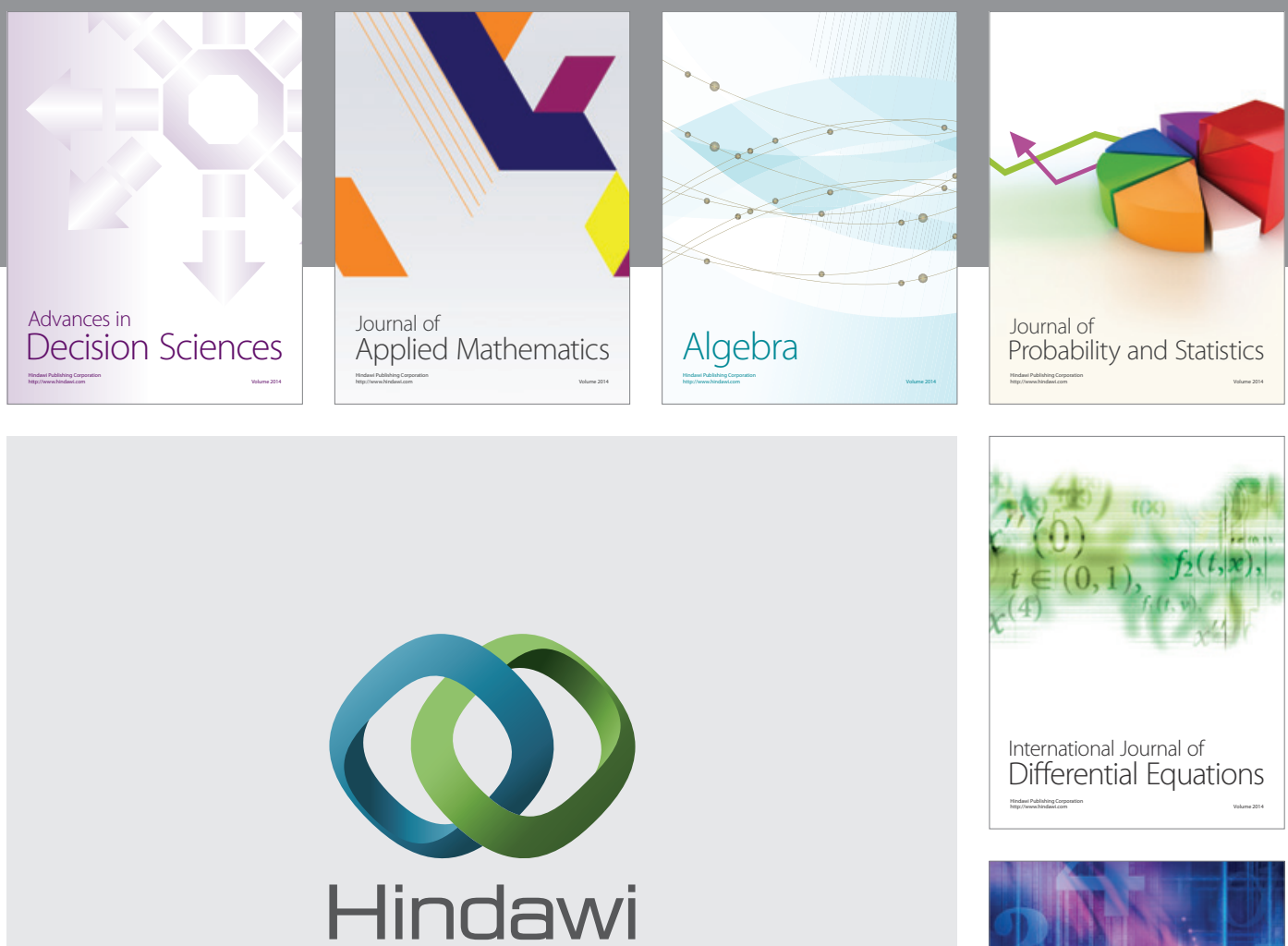

Submit your manuscripts at http://www.hindawi.com
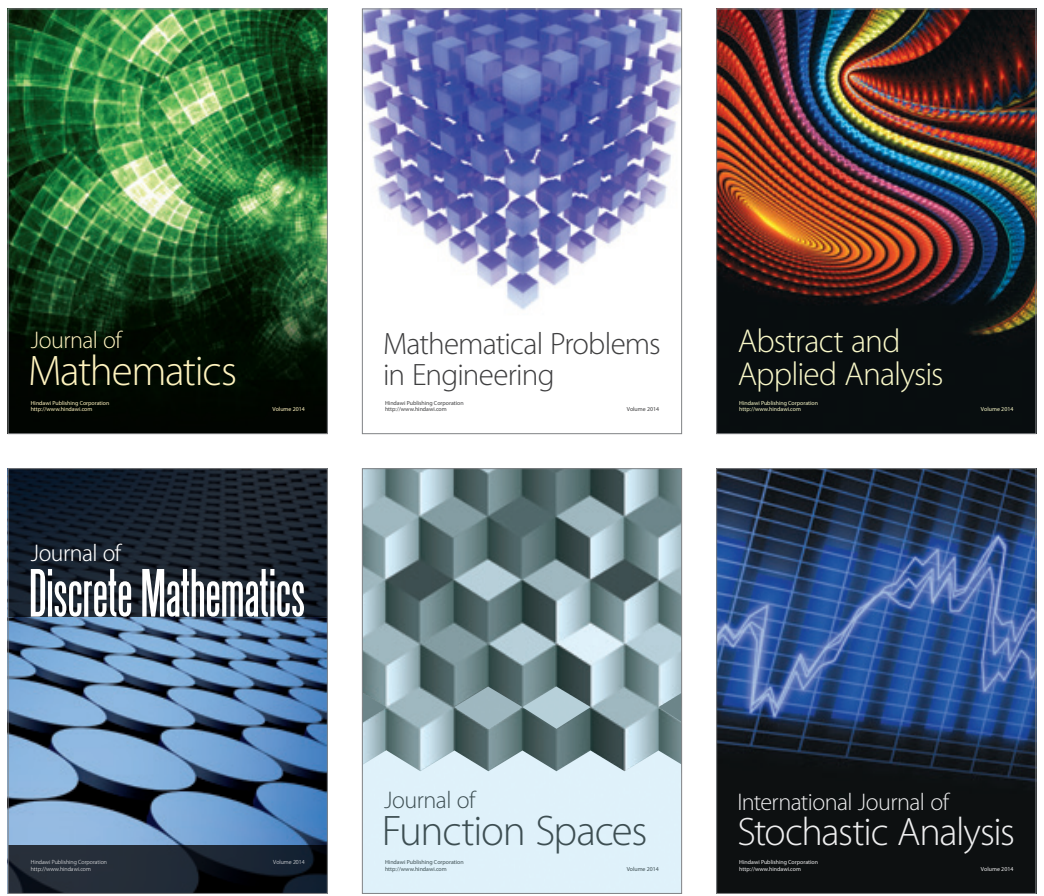

Journal of

Function Spaces

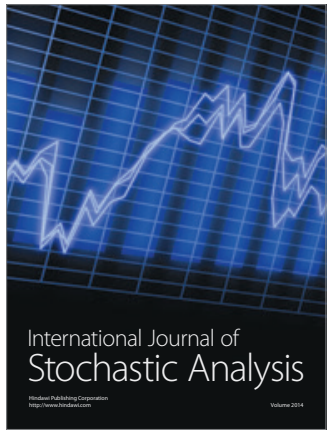

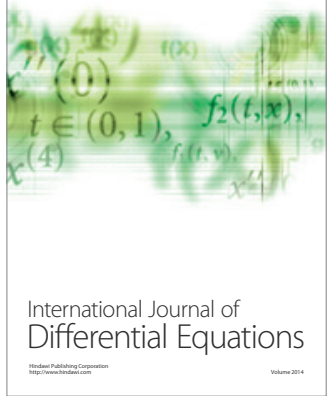
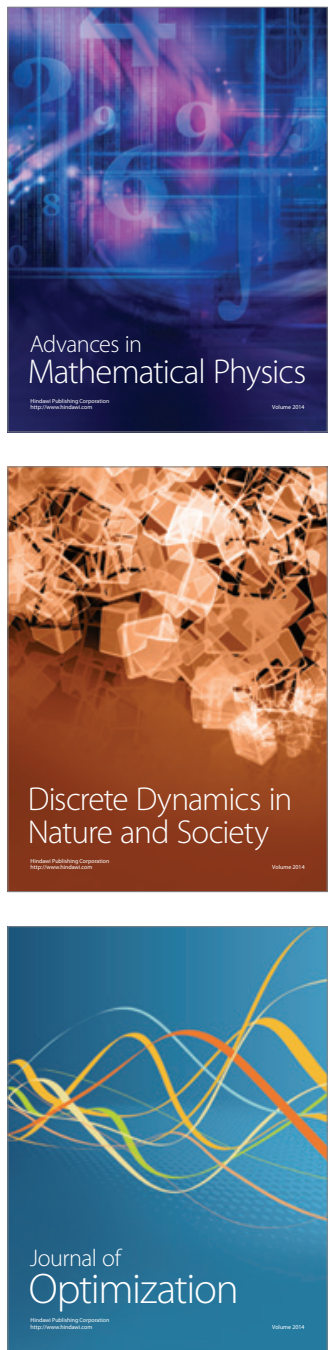